\title{
Implementation of Knowledge Management in Different Industries
}

\author{
Mukhtar Hanafi ${ }^{1, *}$, Andi Widiyanto ${ }^{2}$, Nuryanto ${ }^{3}$, Hafidz Fahrizal Rahman ${ }^{4}$, Mohammad Rahardian Adhitama ${ }^{5}$ \\ Department of Information Technology, Faculty of Engineering, Universitas Muhammadiyah Magelang, Magelang, Indonesia \\ ${ }^{1}$ hanafi@ummgl.ac.id *; ${ }^{2}$ andi.widiyanto@ummgl.ac.id; ${ }^{3}$ nuryanto@ummgl.ac.id; ${ }^{4}$ hafidzfahrizal25@gmail.com; \\ ${ }^{5}$ tamarahardian12@gmail.com \\ * Corresponding author
}

(Received July 4, 2021 Revised August 14, 2021 Accepted August 30, 2021, Available online September 1, 2021)

\begin{abstract}
Customer knowledge is a valuable asset, and gathering, managing, and sharing customer knowledge can be a useful competitive activity for organizations. Successful knowledge partnerships with essential and valuable customers can strengthen business performance and create an absolute competitive advantage that is difficult for competitors to emulate. In consumer knowledge management, companies often experience significant obstacles or constraints so that sometimes many companies prevent them from managing consumer knowledge. The company or organization depends on consumers who do not need to understand the industrial field of the company or organization. This paper discusses the comparison of the application of customer knowledge management in various industries. Research findings that all organizations must apply the three essential components of customer-related knowledge within the underlying conceptual framework. Three basic components of customer-related knowledge within a basic conceptual framework: knowledge for customers, knowledge of customers, and customer knowledge, cannot be eliminated. This proves the compatibility with previous studies. In fact, to succeed, they must be applied so that it is of value to the company. Implementation of the framework can present a great opportunity for the organization or company to make new products so that this will improve the performance of the company or organization and maintain the continuity of the company or organization.
\end{abstract}

Keywords: Knowledge Management; Consumer Knowledge Management; Industries;

\section{Introduction}

Customer knowledge is an important asset, and collecting, managing and sharing customer knowledge can be a valuable competitive activity for organizations [1]. With the emphasis on knowledge as the main competitive factor in the global economy, companies may neglect the main element - customer knowledge [2]. By involving customers in the company's processes, CKM connects the external environment to the internal environment [3] and transfers and shares information not only among customers and within the company but also between customers and the company [4][5]. In fact, in order to achieve a sustainable competitive advantage compared to competitors, it is not only continuous observation of customer perceptions and expectations of the delivered product or service but it is also important to continuously interact with customers to exploit and apply their tacit knowledge [6]. Successful knowledge partnerships with important and valuable customers can strengthen business performance and create an inimitable competitive advantage that is difficult for competitors to imitate.

In managing consumer knowledge, companies often experience significant obstacles or constraints so that sometimes many companies prevent them from managing consumer knowledge [7]. One of the obstacles to implementing CKM is that many companies apply it with the wrong mindset. Many companies misinterpret Customer Knowledge Management in their business activities. Wrong thinking when companies think that Customer Knowledge Management is a tool to increase customer knowledge. Another challenge or obstacle is the dependence on knowledge from consumers. Many companies are too focused and rely on knowledge from consumers without taking any action to process that knowledge [6]. This is supported by the fact that consumers have good knowledge limited to certain industries. In managing consumer knowledge, every company must adapt to consumer conditions and not generalize consumer desires. 
Based on these problems, it can be found that the root of the problem that will be examined in this research is that the company or organization depends on consumers who do not necessarily understand the industry of the company or organization. Based on the problem statement, it was determined that the research question in this paper is: What conceptual framework is suitable for an industry-based company or organization? So this study aims to compare the conceptual framework of each industrial sector based on previous research. The output of this research is expected so that this research can be considered as a reference for companies or organizations in implementing the framework according to their industry.

\section{Literature Review}

\subsection{Knowledge Management}

Knowledge management consists of 2 words, namely management and knowledge. According to the Big Indonesian Dictionary, the definition of management is the effective use of resources to achieve goals [8]. According to Terry [9], the definition of management is a unique and distinctive process consisting of planning, organizing, and mobilizing and controlling what is done to determine direction and achieve predetermined goals through the use of human resources and other resources. Meanwhile, according to Griffin [10], management is the process of planning, organizing, coordinating, and controlling every available resource to achieve the goals or objectives that have been determined effectively and efficiently. Effective means that the goals can be achieved according to the existing plan, and efficient means that it is implemented correctly and organized according to a predetermined schedule. So, to put it simply, management is a way to plan, collect and organize, lead and control resources for a purpose.

According to Oxford Dictionaries, the definition of knowledge is Facts, information, and skills acquired through experience or education; theoretical or practical understanding of a subject [10]. The definition of knowledge in the context of knowledge management is the overall cognition and skills used by humans to solve problems. Knowledge can also be defined as the capacity to take action effectively. Sources of knowledge can come from books, newspapers, people, and various things.

The content of KM is concerned with the definition of what is meant by the term "knowledge." This understanding has an impact on the knowledge management strategy chosen. Knowledge, according to Orange et al. [13], is "the outcome of learning that is personal to an individual." Information is defined as "the expression of knowledge that can be stored, accessed, and transferred." Knowledge may also be characterized as the ability to understand "why," "how," and "who," as well as an intangible economic resource from which future income might be earned. Knowledge, on the other hand, might be viewed as a component of a task-performing system, or as a state of that system that warrants task completion and future repetition. When this component (knowledge) is missing, a task will be completed incorrectly. If this deficiency persists over time, the system will be become obsolete. As a result, when attempting to comprehend information and its administration, the "base of use" and "context of use" are critical factors.

The organizational setting for the application of knowledge is referred to as the KM context. Every organization, according to Stahle [11], is a three-dimensional system with a mechanistic, organic, and dynamic nature, each of which brings various KM problems. The mechanistic component works in the same way as a machine. It focuses on explicit information and may include quality management systems, manuals, and IT tools. The organization's organic character allows it to work more freely and adapt to changing business situations. In this setting, KM is primarily focused on people and involves the management of tacit knowledge. Continuous development and innovation are made possible by the dynamic character of the environment. The emphasis in this system is on networking capabilities to facilitate the work of interdepartmental teams, which is typical of this type of setting.

Another aspect of organizational context is culture, which includes both tacit and explicit cultures (defined by networks, linkages, and interdependence) (defined by their artefacts, e.g. organizational charts, documents, etc.). Work procedures can also be used to determine organizational culture (for example, collaborative versus a competitive culture, informal versus formal, individual versus group, and so on). As a result, the context for knowledge management influences, and is influenced by, the content (knowledge) to be managed.

Knowledge Management (KM) is the process of creating, sharing, using and managing knowledge and information of an organization [11]. Knowledge Management (KM) refers to a multi-disciplinary approach to achieving organizational goals by making the best use of knowledge. KM focuses on processes such as acquiring, creating and sharing knowledge and the cultural and technical foundations that support them [12]. So, it can be simplified, knowledge management is a series of activities used by organizations or companies to identify, create, explain, and distribute knowledge to be reused, recognized, and learned within the organization. These activities are usually linked 
to organizational goals and are intended to achieve certain outcomes such as shared knowledge, improved performance, competitive advantage, or higher levels of innovation.

The concept of knowledge management includes human resource management and information technology (IT) in order to achieve a better corporate organization so that it can win business competition. The development of information technology does play an important role in the concept of knowledge management. Almost all activities of human life will be colored by the mastery of information technology, so when talking about knowledge management can not be separated from management. Knowledge management is the process of planning, gathering and organizing, leading and controlling data and information that has been combined with various forms of thinking and analysis from various competent sources.

\subsection{Consumer Knowledge Management}

Consumer Knowledge Management (Consumer Knowledge Management) is referred to as a strategic practice in progressive companies to gain the ability to transform their customers from passive recipients of products and services to active knowledge-oriented partners Sofianti et al.[13] CKM is about acquiring, sharing, and extending existing knowledge. in the customer that contributes to the well-being of the customer and the company. CKM is described as a continuous process for generating, disseminating, and using customer knowledge within an organization, and between the organization and its customers [14] [15].

Customer knowledge management with respect to customer knowledge acquisition is shared and developed for the benefit of the customer and the organization. Customer knowledge management, which enables organizations, is more likely to identify emerging opportunities in the market and enhance their competitive advantage.

Although they are related to each other, knowledge management (KM), customer relationship management (CKM), and customer knowledge management (KM) have some differences. Customer knowledge can be defined as the process of future needs and preferences through the interaction, observation and analysis of their demand and buying behavior [16]. In general, there are 3 components of customer-related knowledge-based, namely: knowledge for customers, knowledge of customers, knowledge of customers. The three types of customer-related knowledge are shown in Figure. 1.

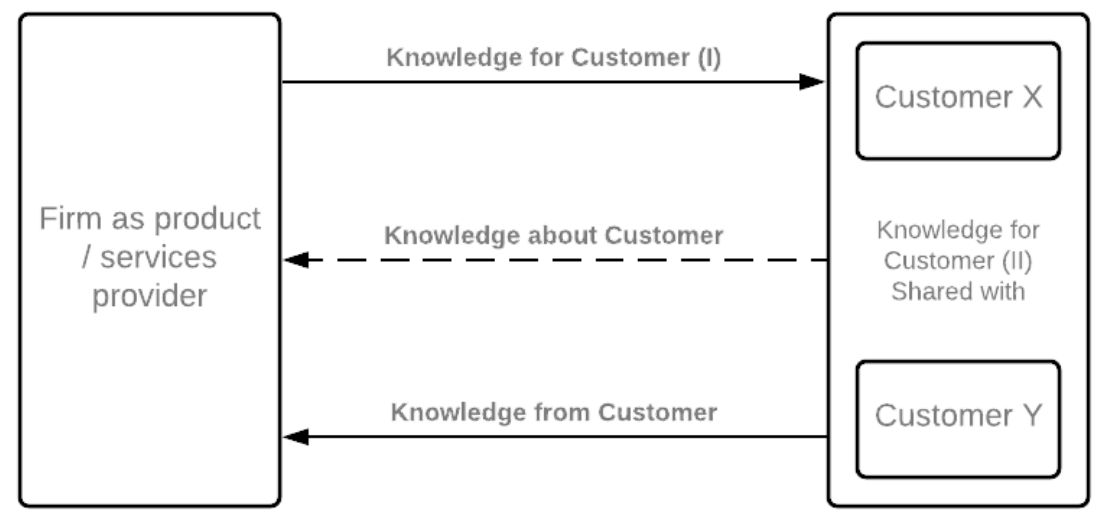

Fig. 1. Three Types of Knowledge related to Customers Knowledge for customers

Knowledge for customers is knowledge provided by an organization to its customers [17]. In other words, this definition refers to the CKM strategies that organizations use to manage the flow of knowledge from the organization to the customers.

Knowledge of the definition of a customer is a customer's background, motivation, expectations and preferences on a product or service. Past, present and future customer needs, wants, tastes and trends. Information regarding customer purchases, payments, motivations, habits and demand patterns [19]. In this customer-related type, companies can gain such knowledge from websites, search portals, surveys, or product catalogs in analyzing and exploring potential customer needs. Most often, this type of knowledge is associated with the design, development and improvement of products and services [17]. 
Knowledge from customer definition is the acquisition of knowledge from customers for product and service improvement. Information or knowledge that customers share with the company through their feedback [19]. The customer is a strategic opportunity to learn because of the knowledge that the company has on the customer's knowledge [2]. Understanding what users know, what they need is an important role. Feedback from customers helps companies to continuously develop products and services, define market segments more effectively, build good business strategies and create new products and innovative services [13]. Smith and James [20] add one component to consumer knowledge, namely knowledge co-creation. This conceptual framework is shown in Figure 2.

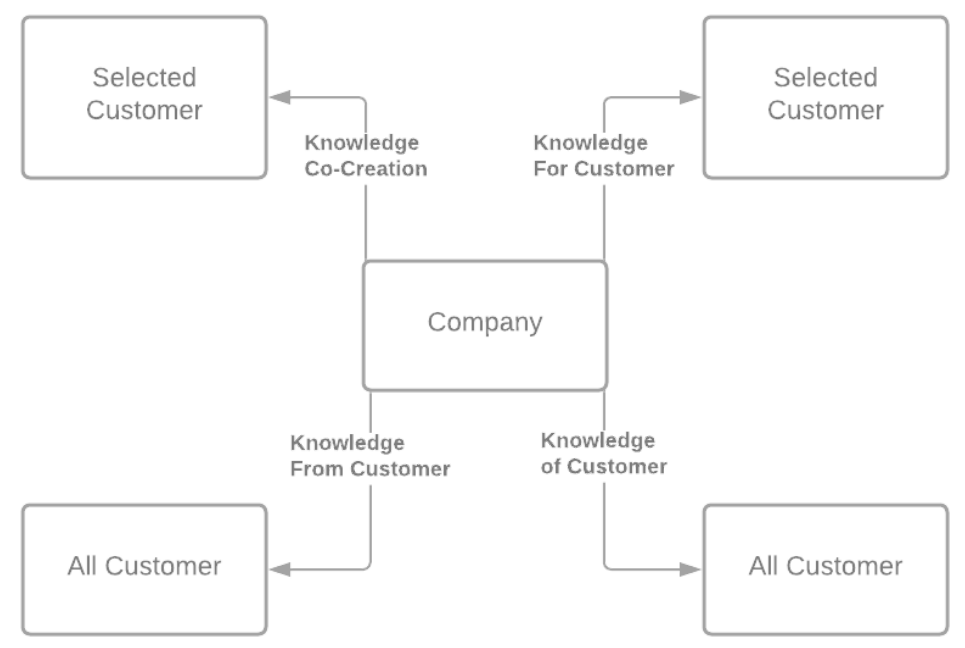

Fig. 2. CKM Conceptual Framework

The definition of co-creation of knowledge is knowledge of the two-way relationship between the customer and the company. Knowledge management is becoming a way to facilitate interactions between customers and companies to form new knowledge, products and services [13]. Customer knowledge can also be further dissected into four dimensions namely objective, subjective, specific and general knowledge in which each component is expected to be correlated [21]. Their dimensions and definitions are shown in Table 2.

Table. 2. Customer knowledge dimensions

\begin{tabular}{|c|l|}
\hline Customer Knowledge Dimension & \multicolumn{1}{|c|}{ Definition } \\
\hline Objective Knowledge & $\begin{array}{l}\text { Measures how much factual knowledge consumers have } \\
\text { about the product, its attributes, and the relationship } \\
\text { between different product attributes and their } \\
\text { relationship to performance }\end{array}$ \\
\hline Subjective Knowledge & $\begin{array}{l}\text { Measuring consumer perceptions of how much they } \\
\text { know about a product }\end{array}$ \\
\hline Specific Knowledge & $\begin{array}{l}\text { A type of knowledge that is more detailed than general } \\
\text { knowledge }\end{array}$ \\
\hline General Knowledge & $\begin{array}{l}\text { General level knowledge that can be accessed and } \\
\text { learned by anyone }\end{array}$ \\
\hline
\end{tabular}

\section{Method}

The first stage is the activity of collecting data to find the root of the problem and determine research questions. In the process of determining the research question, the main consideration is that the answer to the research question is expected to find a solution to the problem at hand. 
The second stage is to conduct a literature study from various credible and responsible sources. Sources of literature studies in this research come from scientific books, journals, scientific websites. In the analysis phase, a comparison of the conceptual frameworks is carried out in each industry field. The result of this stage is the conceptual conclusion of each industrial framework. The methodology in this study is shown in Fig. 3.

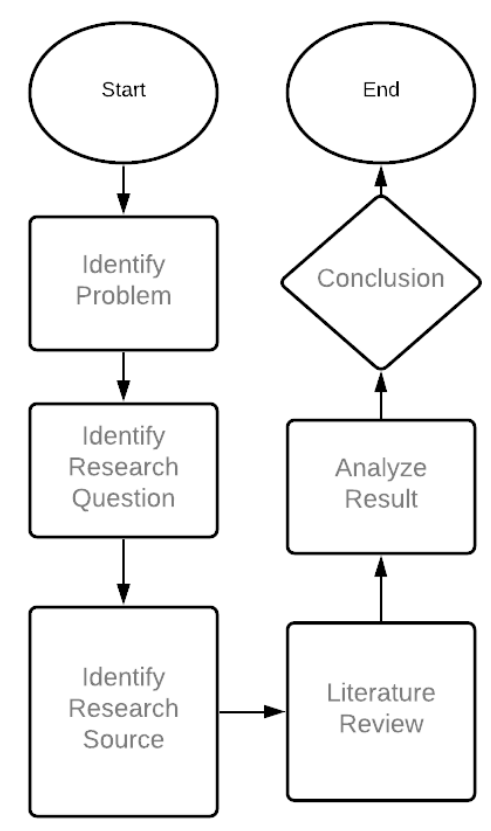

Fig. 3 Research Methodology Flowchart

\section{Result and Discussion}

The results of desk research by reading various scientific and reliable sources, the findings are as follows.

\subsection{Findings in the Banking Industry}

In the banking industry, banks can share information about their operational processes such as setting interest rates and different financial schemes with customers. In fact, many financial institutions are now disclosing hidden fees to customers to build trust and confidence. In this sector, information about customers such as demographics and customer income helps banks to offer new services more quickly and maintain standards that meet customer expectations [22]. The conceptual framework for the banking sector is shown in Fig. 4.

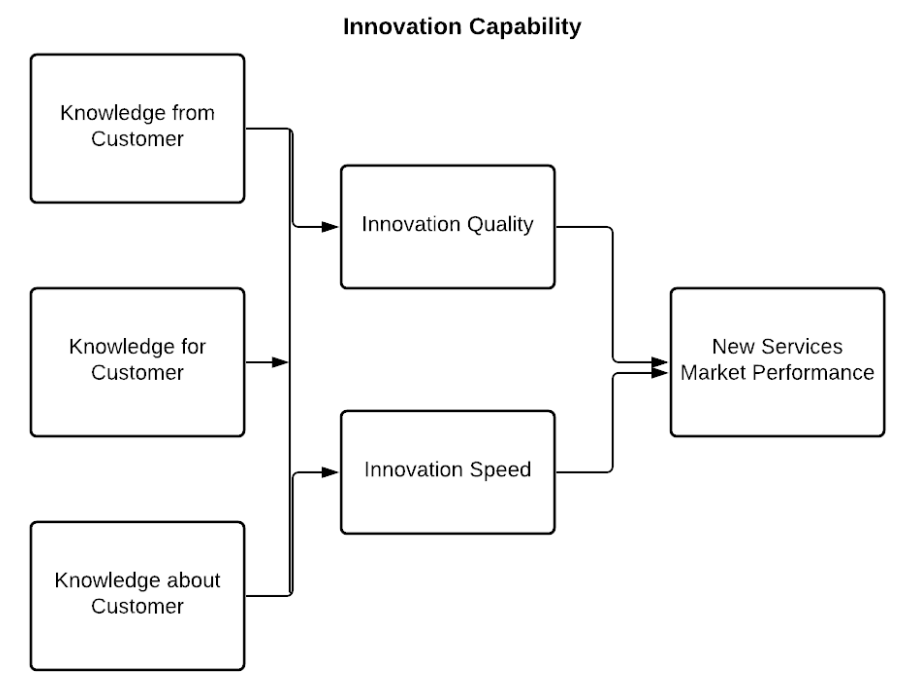

Fig. 4. CKM Conceptual Framework for the Banking Sector 
M. Hanafi et al / IJIIS vol. 4, no. 2, September 2021, pp 103-111

Taherparvar et al [5] concluded that innovation ability plays a specific role between CKM and performance. In particular, CKM is necessary, but not sufficient for excellence in performance, while the potential value of CKM is realized through effective innovation capabilities [5]. The speed of innovation and the quality of banking products have a very vital role in growing customer trust. In some cases, after the bank launches a new product, in a short time it can meet customer expectations. this means that the bank has optimized CKM.

\subsection{Findings in the Telecommunications Industry}

$\mathrm{Wu}$ et al. [17], investigated the linking mechanism between customer knowledge management and IT-enabled business model innovation. In a study conducted by $\mathrm{Wu}$ et al [17], it was found that the process of value delivery and value taking to innovate is supported by IT. It was found that the role of IT is very important in linking CKM and business model innovation. This conclusion is based on the fact that the relationship between CKM and business model innovation greatly facilitates interaction or knowledge transfer at low costs. Meanwhile, IT can help companies capture revenue from revenue and lower operating costs, which forms the basis of a profitable and sustainable business model.

It was found that business model innovators should see their customers as partners in acquiring new knowledge [17]. Organizations or companies must actively implement IT to improve communication. In this industry companies in particular must use IT as a strategic support company to gain value. Companies in this industry benefit greatly from a multi-stage approach to IT implementation, making it very easy to innovate business models. This can backfire because the company is required to compete with other companies in the same industry. Therefore, companies or organizations in this industry are required to use IT as much as possible so that they can innovate effectively and quickly [23].

With the convenience obtained because of the existence of IT, it is hoped that there will also be proactive customers in providing input or at least supporting the organization to grow. Not a few find that a more active consumer attitude can help companies or organizations find new innovations for their business development. The active attitude of consumers can indirectly increase opportunities for companies to improve their performance, so that this benefits both parties.

\subsection{Findings on Marketing Service Firms}

Daghfous and Jeremy [25] found that the results of their study indicate that customer absorption capacity affects the role of knowledge for customers in the end whether customer development will occur. Where tacit knowledge transfer occurs, it is limited to loyal customers and tall. With respect to transfer methods, the findings reveal that knowledge-intensive business service firms transfer explicit knowledge using both formal and informal methods [24].

Managers should be open to using different types of media in transferring explicit and tacit knowledge rather than limiting themselves to the normative "lean-formal-media-normative" categorization versus the "rich-media-informal-media" categorization in the literature. Understanding the role of customer knowledge transfer in the development of an organization's existing customers is critical in the context of a knowledge intensive business service company. The existing literature recognizes that customer development efforts are critical in increasing service adoption and firm performance but there is a dearth of research on customer knowledge transfer in the context of professional service organizations [24].

In marketing companies, there is a need for two-way communication in dealing with consumers. Therefore, in the conceptual framework, there are 4 components in implementing CKM. The four components correspond to the conceptual framework designed by Smith and James [20] in Figure 2. In this industry, the knowledge co-creation component plays a very important role. The four required customer-related knowledge-based components are: knowledge for customers, knowledge of customers, knowledge of customers, and co-creation of knowledge.

\subsection{Findings in the Food and Beverage Retail Industry}

Chuan and Banerjee [25] used a case study at Starbucks in their research on the use of social media as a CKM application. Starbucks uses Twitter (MBS), Facebook (SNS), Foursquare (LMS) and MyStarbucksIdea (CDS) to support various aspects of its CKM strategy. Specifically, Twitter, Facebook and MyStarbucksIdea are used for knowledge management for, from and about customers, while Foursquare is mainly used for managing knowledge for and from customers.

Starbucks example to illustrate that social media is not an exclusive tool for online businesses [25]. The use of social media can be considered as one of the main keys in this sector. Like previous research, social media has proven to be effective as Starbucks branding and marketing. Starbucks draws knowledge from customers in analyzing their inputs, 
behaviors, and preferences. In fact, Starbucks does not treat using other applications other than social media in utilizing CKM. Customers can also actively provide feedback to Starbucks about their innovations through social media. This is very well used by Starbucks to create innovations for its products. The implication is that organizations should use social media to give a boost to their business by absorbing customers in their operations [25]. Another thing that should be noted, that Starbucks still maintains the intensity of promotion through social media that is not excessive. So this is a separate value for Starbucks in the eyes of its customers.

It can be concluded that for the fast food retail industry, the basic framework of knowledge related to customers in Figure 1 is still very feasible to use.

\subsection{Findings in the Sports Services Industry}

Behnam et al [26] investigated the effect of CKM on consumer loyalty in the sports services industry.

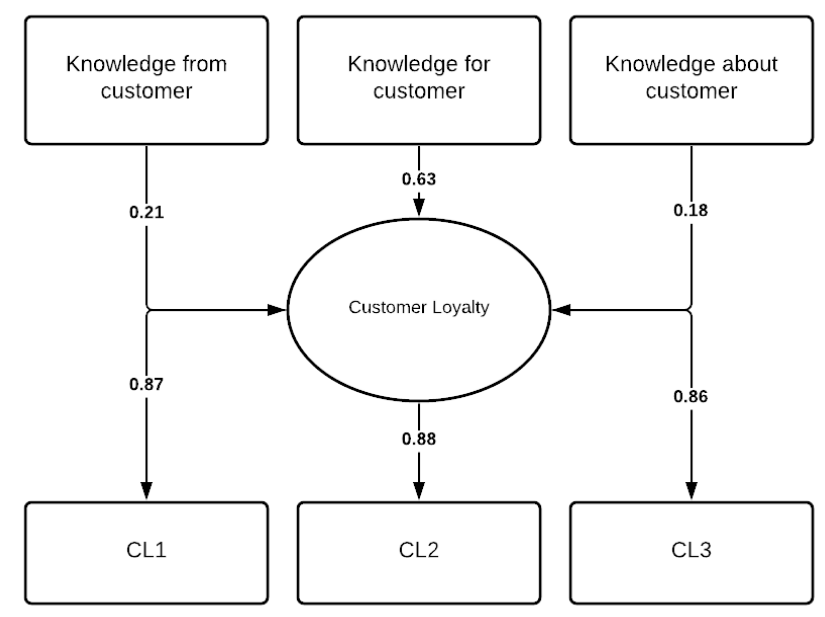

Fig. 5 Standardized Model 1 Weight

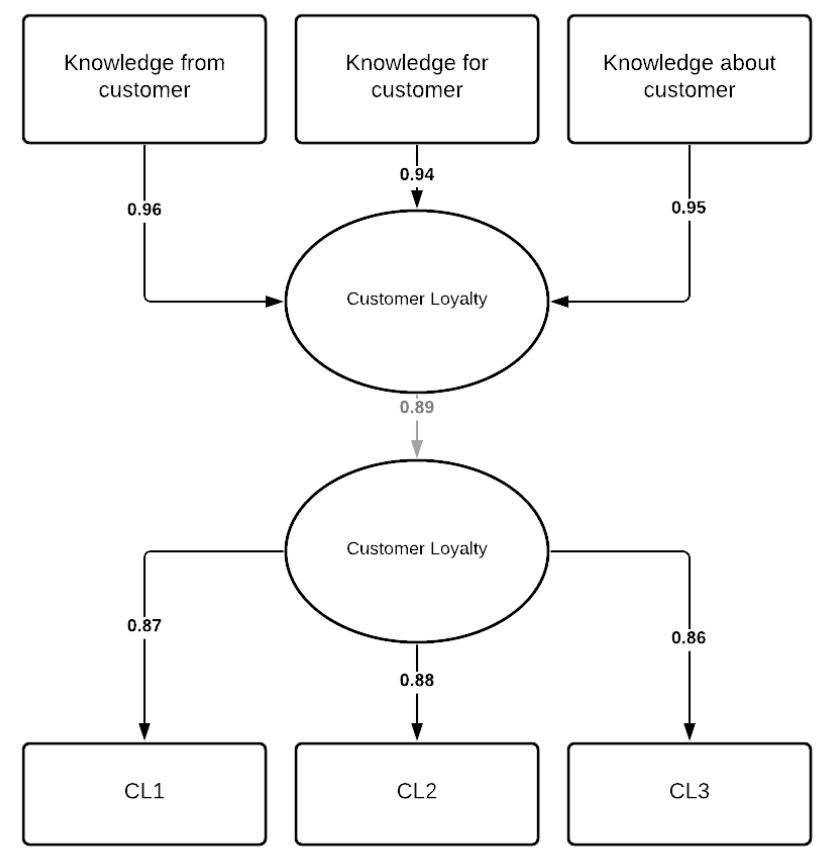

Fig. 6 Model Weight Standards

According to Fig. 6 and Fig. 7, component knowledge about customers shows the greatest influence on customer loyalty. This shows a sports service company should know what customers expect from the company's services. 
M. Hanafi et al / IJIIS vol. 4, no. 2, September 2021, pp 103-111

Behnam et al [26] showed that CKM and its components have influenced customer loyalty. Customer requests about the current quality of sports services and work to improve service quality based on customer ideas and needs, Awareness will be obtained from customer requests and requests and apply them to practice and solve existing problems.

\section{Conclusion}

The three basic components of customer-related knowledge within a basic conceptual framework: knowledge for customers, knowledge of customers, and knowledge of customers, cannot be eliminated. This proves that it is in agreement with previous studies conducted by Aho and Uden [14], and Khosravi and Hussin [15]. In fact, to succeed, they must be implemented in order to be of value to the company. With the implementation of the framework can present great opportunities for organizations or companies to create new products so that this will improve the performance of the company or organization and maintain the continuity of the company or organization. The limitation of this research is that there is no company scale categorization. The scale of the company allows for different CKM implementations. As an example of the implementation of CKM in Indonesia, for example in the field of Maritime Transportation such as port services [27].

\section{References}

[1] F. Khodakarami and Y. E. Chan, "Exploring the role of customer relationship management (CRM) System customer knowledge creation," Information and Management, vol. 51, pp. 27-42, 2014.

[2] M. Gibbert, M. Leibold and G. Probst, "Five Styles of Customer Knowledge Management, and How Smart Companies Use Them To Create Value," European Management Journal, vol. 20, no. 5, pp. 459-469, 2002.

[3] Y.-S. Chen, "The Positive Effect of Green Intellectual Capital on Competitive Advantage," Journal Of Business Ethics, vol. 77, no. 3, pp. 271-286, 2008.

[4] Z. I. J. Zhang, "Customer knowledge management and the strategies of social software," Business Process of Social Software Journal, vol. 17, no. 1, pp. 82-106, 2011.

[5] N. Taherparvar, R. Esmaeilpour and M. Dostar, "Customer knowledge management, innovation capability and business performance: a case study of the banking," Journal of Knowledge Management, vol. 18, no. 3, pp. 591-610, 2014.

[6] S. Jaurianty, M. Y. Jinca, and E. S. Manapa, "Stakeholder Knowledge of Sustainable Road Implementation In Buru Regency," IOSR Journal of Mechanical and Civil Engineering (IOSR-JMCE), vol. 15, no. 2, pp. 38-42, 2018.

[7] A. Nova, "Binusian Blog Community," Bina Nusantara, 4 June 2010. [Online]. Available: http://krylanceo.blog.binusian.org/2010/06/04/kendala-dalam-penerapan-ckm/. [Accessed 2810 2018].

[8] "Big Indonesian Dictionary," Language Development and Development Agency, Ministry of Education and Culture of the Republic of Indonesia, [Online]. Available: https://kbbi.kemdikbud.go.id/. [Accessed October 1, 2015].

[9] A. Y. Afif, "Rocket Management," September 7, 2018. [Online]. Available: https://rocketmanajemen.com/20-definisi-manajemen-menurut-para-ahli/\#a. [Accessed 1011 2018].

[10] "Oxford Dictionaries," Oxford University Press, 2018. [Online]. Available: https://en.oxforddictionaries.com/definition/knowledge. [Accessed 1011 2018].

[11] J. Girard and J. Girard, "Defining knowledge management: Toward an applied compendium," Online Journal of Applied Knowledge Management, vol. 3, no. 1, 2015.

[12] S. Liu, "Introduction to Knowledge Management," University of North Carolina at Chapel Hill, [Online]. Available: http://www.unc.edu/ sunnyliu/inls258/Introduction_to_Knowledge_Management.html. [Accessed 10 11 2018].

[13] Sofianti, Suryadi, Govindaraju and Prihartono, "Customer Knowledge Cocreation Process in New Product Development," in World Congress on Engineering, London, 2010. 
M. Hanafi et al / IJIIS vol. 4, no. 2, September 2021, pp 103-111

[14] A.-M. Aho and L. Uden, "Customer Knowledge in Value Creation for Software Engineering Process," Internal Conference on Knowledge Management in Organizations: Service and Cloud Computing, vol. 7, pp. 141-152, 2012.

[15] A. Khosravi and A. R. C. Hussin, "Customer Knowledge Management: Development Stages and Challenges," Journal of Theoretical and Applied Information Technology, vol. 91, no. 2, 2016.

[16] S.-M. Tseng and P. H. Wu, "The impact of customer knowledge and customer relationship management on service quality," International Journal of Quality and Service Science, vol. 6, pp. 77-96, 2014.

[17] J. Wu, B. Guo and Y. Shi, "Customer knowledge management and IT-enabled business model innovation: A conceptual framework and a case study from China," European Management Journal, vol. 31, no. 4, pp. 359-372, 2013.

[18]H. Gebert, M. Geib, L. Kolbe and W. Brenner, "Knowledge-enabled customer relationship management: integrating customer relationship management and knowledge management concepts," Journal of Knowledge Management, Vol. 7 No. 5, 2003, pp. 107-23, vols. 7, no. 5, pp. 107-23, 2003.

[19] K. F. Adrutdin, A. Ali, J. Jaafar, S. Hassan and N. S. Rahim, "A Study of Retail Islamic Banking: The Relationship between Customer Knowledge and Service Quality," Internal Journal of Supply Chain Management, vol. 5, no. 2, pp. 115-21, 2016.

[20]H. A. Smith and J. D. McKeen, "Development in Practice XVIII-Customer Knowledge Management: Adding Value for Our Customers," Communications of the Association for Information Systems, vol. 16, no. 36.

[21] V. Y. Yoon, R. E. Hostler, Z. Guo and T. Guimaraes, "Assessing the moderating effect of consumer product knowledge and online shopping experience on using recommendation agents for customer loyalty," Decision Support System, vol. 55, no. 4, pp. 883-893, 2013.

[22] S. K. Taghizadeh, S. A. Rahman and M. Hossain, "Knowledge from customer, for customer, or about customer: which triggers innovation capability the most?," Journal of Knowledge Management, vol. 22, no. 1, pp. 162-182, 2018 .

[23] T. W. Sagala, T. Wati, Solikin, N. F. A. Budi and A. N. Hidayanto, "Analysis and Implementation Measurement of Semantic Similarity Using Content Management Information on WordNet," 2018 International Conference on Advanced Computer Science and Information Systems (ICACSIS), Yogyakarta, 2018, pp. 337-342.

[24] A. Daghfous and N. J. Ashill, "Transferring knowledge for organizational customers by knowledge intensive business service marketing firms: An exploratory study," Marketing Intelligence and Planning, pp. 421-442, June 2013.

[25]A. Y. Chua and S. Banerjee, "Customer Knowledge Management via Social Media: The case of Starbucks," Journal of Knowledge Management, vol. 17, no. 2, pp. 237-249, 2013.

[26] M. Behnam, S. N. Sajjad, M. J. Farahani and E. A. Ghahfarokhi, "The Influence of Customer Knowledge Management on Customer Loyalty in Sport Service Industry," Sport Science, vol. 9, pp. 93-97, 2016.

[27]E. S. Manapa, "Optimization of Fisheries Port Services of the Ambon Archipelago Based on Supply and Demand of Captured Fish," IPB Dissertation, 2012 